\title{
Digital Spirometer with LabView Interface
}

\author{
Alejos-Palomares R., *Ramírez Cortes J.M., Domínguez-Martinez N. \\ Computing, Electronics and Mechatronics Department, University of the Américas, \\ Puebla, Cholula, México \\ Electronics Department, *National Institute of Astrophysics, Optics and \\ Electronics, Tonantzintla, Puebla, Mexico \\ ruben.alejos@udlap.mx
}

\begin{abstract}
In the present document, the design and the construction of a low cost digital spirometer is presented like a basic tool for evaluate of the respiratory capacity. A Spirometer is the ideal instrument to measure the mechanics ventilatoria in respiratory studies that allow the analysis, determination and monitoring of diverse human respiratory diseases like asthma, pulmonary embolism, respiratory bronchitis and others deficiencies. The spirometer developed is an instrument portable, of easy handling and computerized that fulfills with the American norms given by the American Thorax Society (ATS) and the requirements of the Mexican population. By means of digital electronics and a pneumotachometer, the virtual instrument acquires and processes the respiratory flow using a NI USB interface. The volume-time and flow-volume graphs are displayed means a virtual instrument developed in Labview. The spirometrics test includes parameters of the mechanics ventilatoria like the FEV1 (Forced Expiratory Volume in the first second), FVC (Forced Vital Capacity), and MEF (Maximum Expiratory Flow).
\end{abstract}

Index Terms-Spirometrics, Virtual instruments

\section{Introduction}

Spirometer is the measurement instruments most used in the evaluation of the pulmonary capacity. From its invention in the year of 1846, its use has become popular at world-wide level. At the present time, the spirometers are in their majority portable and usually computerized. They are constituted by a mechanical and/or an electronic sensor, a processor and a printer or another one alternative way of graphical data presentation of any of the following information:

- Graphical measurements of curves volume-time.

- Graphical measurements of flow-volume (spirograms).

- FVC (forced vital capacity); and:

- FEV1 (Forced Expiratory Volume in the first second).

- General Information about the patient.
At the present time recommendations for the standardization of spirometers exists, for example those of the ATS (American Thoracic Society), OSHA (Occupational Safety \& Health Administration), NIOSH (National for Institute Occupational Safety and Health) and ERC (European Respiratory Committee). These recommendations mainly apply to the physical part and some requirements of the unfolding of data.

In the international sport scope, this test is commonly made like control in the evolution of the pulmonary capacity of the sportsmen, reporting itself like a very useful tool for the supervision of the health of high performance sportsmen. [1]. According to information provided by the National Institute of Respiratory Diseases (INER), in spite of being a test not so complex, in our country it is made frequently with errors in the measurement. By this reason, currently in Mexico and Latin America, there are works pointed to standardize this test with the purpose of making its use more efficient.

The test of pulmonary function (PTF) allows: (1) evaluate and quantify the pulmonary capacity and respiratory deficiencies, (2) diagnostic of different types of respiratory diseases, (3) evaluation of the answer of patient to the therapies by upheavals already determined, and; (4) Estimate the risk of a surgery well-knowing the pulmonary capacity.

\section{Physical laws of the respiratory system}

In this section the laws that govern the physical behavior of the respiratory flow will be revised, according to the physiological characteristics of the respiratory system. These laws specifically constitute the base of the operation of spirometer of flow, reason why, special attention in the considerations will be put to apply them. The air like other fluids moves of a region from greater pressure to another one of smaller pressure. The gas interchange in the organism is possible by means of the presence of a differential pressure in the interior of the lung and an external force. In normal conditions, the inspiration happens when the alveolar pressure 
falls below the atmospheric pressure $\left(0 \mathrm{cmH}_{2} \mathrm{O}\right)$. The movement of the diaphragm and the walls of the chest by intercostals muscles produces the force to obtain that negative pressure, finding opposition to the movement by the presence of mobile resistance of the walls of the lung and, by the friction force before the flow of the gas in the lung, weave of the thoracic wall and aerial routes. The work required to overcome the skin friction is lost, but the work made to overcome the mobile defense of the walls is stored, of form similar like happen in the Hooke's law, and used in the expiration, allowing that this last action be a movement passive and periodic.

The movement of the air when breathing presents two types of flow: laminar and turbulent. In the laminar flow the particles of the fluids move throughout adjacent laminas without mixing itself. The agitation of particles in the fluid is only of molecular nature and they are restricted to move essentially in parallel trajectories, due the effect of the fluid viscosity. The study of the laminar flow is described by the law of Poseuille. In the turbulent flow, the particles flowing do not remain in layers, but that moves in heterogeneous form through the flow, sliding beyond other particles and hitting some others, producing fast and continuous mixing of the flow. The measurement of turbulence is described by the Reynolds's number. Because in the turbulence the movement of the small masses of fluid is chaotic, still in small distances, it mathematically turns out unrealizable to determine the movement of individual particles of the fluid. Nevertheless, considering the movement average of the particle aggregations of fluid or by means of statistical methods, it is possible to be obtained mathematical relations The law of Poiseuille, also call Hagen- Pouisuille (Gotthilf Heinrich Ludwig Hagen and Jean Louis Marie Poisuille), is a physical law formulated in 1840 concerning the volume of laminar or liquid stationary flows viscous incompressible uniforms and that happen through a cylindrical tube defined by Streeter [18]:

$\Phi=\frac{d v}{d t}=v \pi R^{2}=\frac{\pi R^{4}}{8 \mu}\left(-\frac{\Delta P}{\Delta x}\right)=\frac{\pi R^{4}}{8 \mu} \frac{\left|P_{1}-P_{2}\right|}{L}$

where:

$\Phi$ is the flow expressed in $\mathrm{m}^{3} / \mathrm{s}$,

$v \quad$ is the volume of a liquid transferred in the time expressed in $m^{3}$

$v$ is the median of the velocity expressed in $\mathrm{m} / \mathrm{s}$,

$x$ is the direction vector del flow expressed in $m$,

$R$ is the internal radius of the pipeline given in $m$,

$\Delta P$ is the differential pressure between the two expressed terminals in $P a$, $\mu$ is the dynamic viscosity of the fluid given in $(\mathrm{Kg} / \mathrm{m} \cdot \mathrm{s}) \times 10^{-5}$

$L \quad$ is the length del tube written in $m$

The complete deduction can consult in the reference [ 21 ]

\section{Spirometer structure}

The diagram to blocks of spirometer of flow appears in Fig. 1. This one consists of a sensor of gaseous flow (pneumotachometer) based in a differential pressure transducer, a 12 bits A/D converter, and a device which includes the hardware conditional system and an interface for software development.

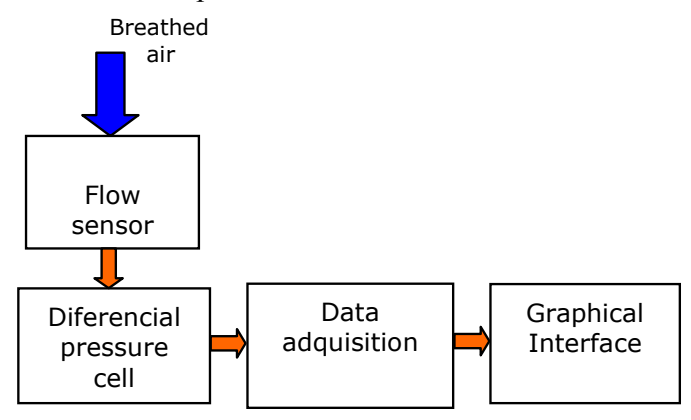

Fig 1: Spirometer structure

The ATS requests the following minimum technical requirements in the design of spirometer: (1) must guarantee the measurements of flow in liters with an exactitude of 0,2 lts/s in the full scale range from 0 to $12 \mathrm{lt}$, (2) the differential pressure sensors must be linear with compensation of temperature and to measure in the range of $+196,133 \mathrm{~Pa}$. (3) must realize the conversion from analogical to digital with a minimum resolution of 12 bits. The following sections will describe the blocks of which consists the spirometer.

\section{Pneumotachometer.}

The pneumotachometer are sensors of gaseous flow that transforms the primary signal, that is to say, the air breathed by the patient, in a proportional differential pressure to the flow according to the Pouisuille's law. This differential pressure is produced by the presence of a pneumatic resistance in a nozzle. Sensitivity depends on the geometric structure of the pneumotachometer that can present/display two classes: The type Fleisch where the resistance is implemented with capillaries; and the type Lilly where the restriction to the flow is implemented by membranes. In this work we use the configuration pneumotachometer type Lilly. 


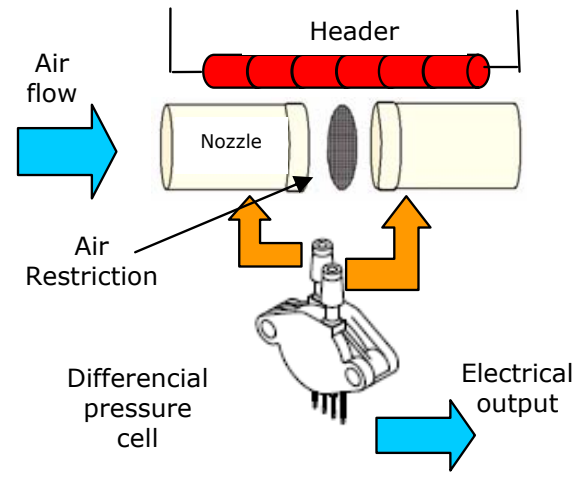

Fig 2 Lilly's Pneumotachometer

For the validity of the measurement of spirometer, the ATS demands the following technical requirements for the acquisition system: The differential pressure sensors must be linear with compensation of temperature and to measure in the $+196,133$ range of $\mathrm{Pa}$. The Pneumotachometer must have a heater who prevents the condensation of the water steam of the expiration; this element can be identified in fig 2. Of the same form it must have a differential pressure transducer that allows to turn the pressure differential into a proportional electrical signal. The pressure sensor is a MPX10 of Motorola of silicon staringauges (Figure 3 ) with a rank of measurement from 0 to $10 \mathrm{kPa}(0-1,45 \mathrm{psi})$, a sensitividad of $70 \mathrm{mV}$ with a typical feeding of 5 volts, the characterization of the signal of the output of the pneumotachometer when the air flow to constant temperature is showed in fig. 3

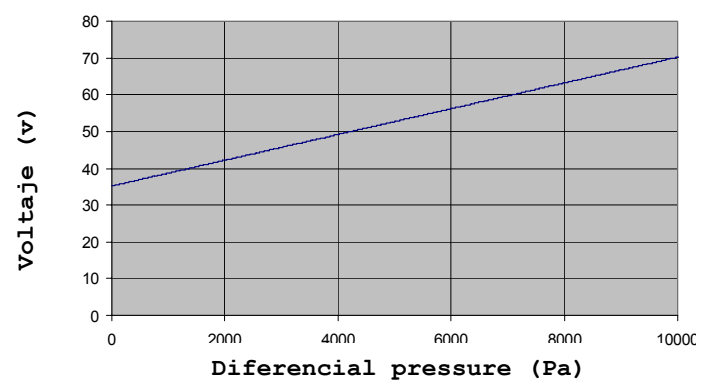

Fig 3 Pneumotachometer response

For the temperature control two $6 \Omega$ heating resistances in the interior of pneumotachometer. The temperature control makes use of a temperature sensor LM35 placed in a flank of pneumotachometer.

\section{Data acquisition}

The conversion of the amplified signal originating in the transducer requires to be turned to digital for its processing by the computer. It is required that the conversion has a resolution of 12 bits by requirement of the ATS, and is desired that the data transmission is made via USB. The most attractive option is to use a simple data acquisition board like the USB-6008 of National Instruments which is easy to use, re-usable, didactic, durable and of low cost. The NI USB-6008 has 8 inputs of $10 \mathrm{v}$ and 2 analog outputs of $2 \mathrm{v}, 12$ digital input/output channels and their internal converter with 12 bits resolution sampling ratio of 10,000 samples/s. The NI USB6008 card can be configures and controlled by means of the application Labview, that it is a developing software to create programs of virtual instrumentation by means of a graphical programming language. In order to be able to use this card it is necessary to prepare the pressure sensor input signal by an instrumentation amplifier. This instrumentation amplifier was configured to obtain a gain of 1000 the output signal obtained from differential pressure sensor is showed in fig 5 .

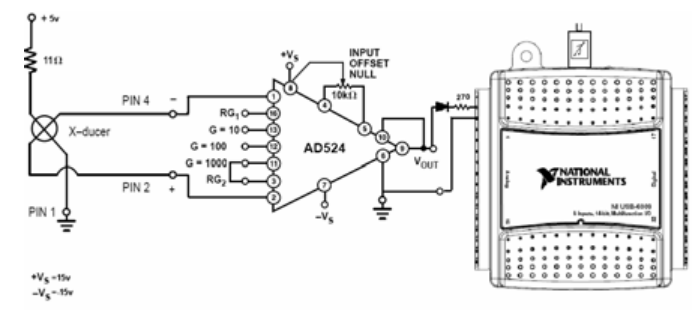

Fig.4 Conditioning of transducer signal

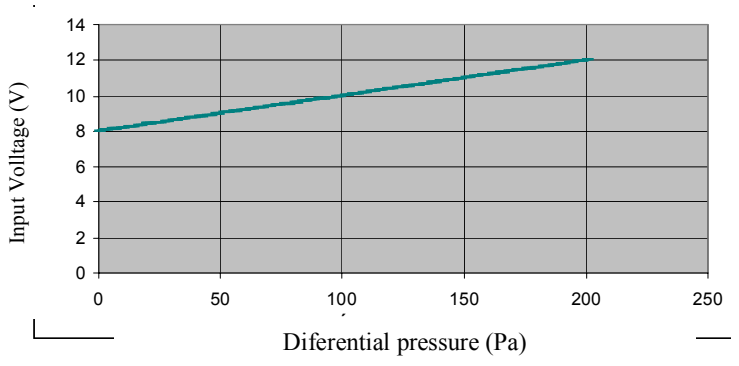

Fig 5 Input signal to NI acquisition data board

\section{Signal conditioning}

The signal conditioning is totally carried-up within the virtual instrument. Ideally the voltage of the sensor is only function of the pressure due to the flow expiratory. If the sensibility of the sensor is of $35 \mathrm{mV} / \mathrm{Pa}$, being able to measure until $10 \mathrm{KPa}$ then the output of the sensor is

$$
V p_{\text {ideal }}=\frac{35 m \text { Volts }}{10000} \cdot \Delta P_{e s p}
$$




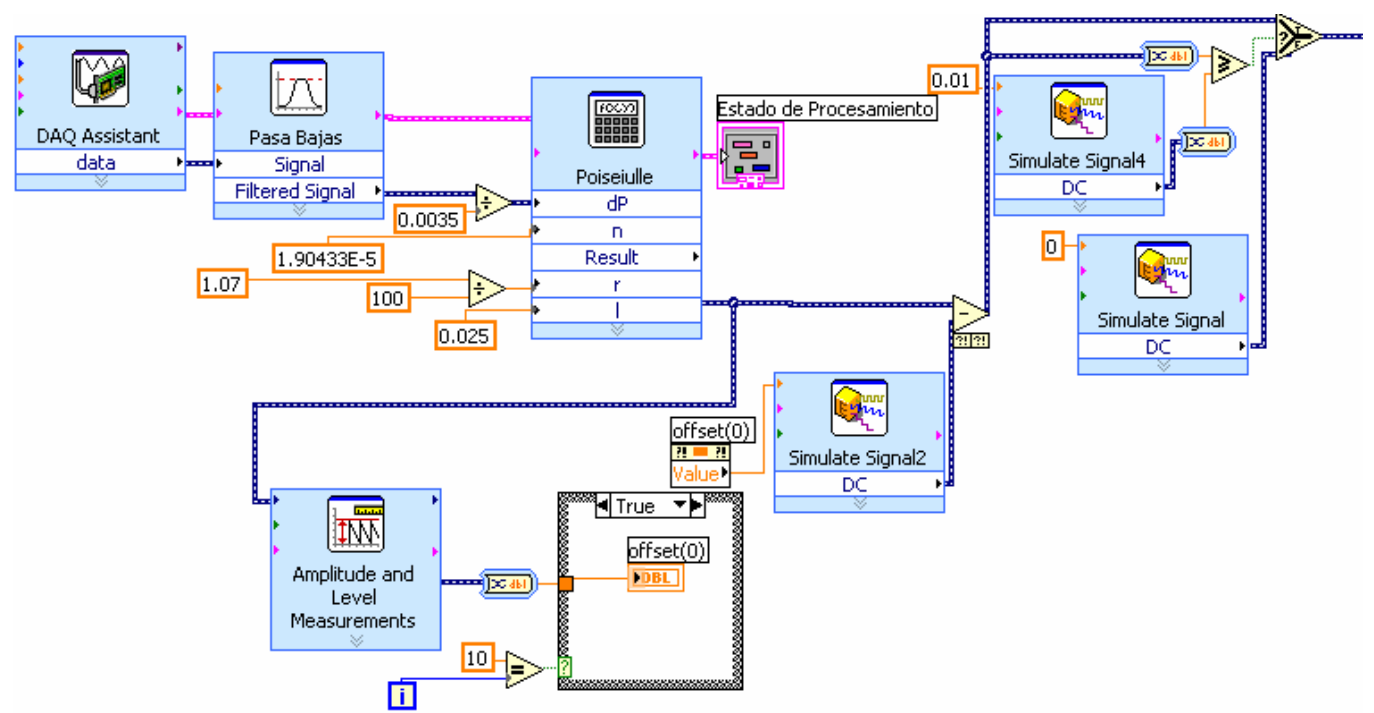

Fig 6. Labview Signal conditioning flow

As the voltage obtained from the transducer presents an offset given by a constant, the real voltage provided by the sensor is:

$$
V p_{\text {real }}=V p_{\text {ideal }}+k_{1}
$$

When amplifying analogically the signal by means of an instrumentation amplifier and blocking the negative currents with the diode, the input voltage is:

$$
V_{\text {amplificado }}=1000 \cdot\left(V p_{\text {ideal }}+k_{2}\right)-V_{\text {diodo }}
$$

Therefore the differential pressure necessary for the calculation of the flow according to (1) will be given by:

$$
\begin{aligned}
& \Delta P_{e s p}=\frac{V_{\text {amplificado }}-1000 k_{2}+V_{\text {diodo }}}{3.5 m \text { Volts }} \\
& \Delta P_{\text {esp }}=\frac{V_{\text {amplificado }}}{3.5 m \text { Volts }}-k_{3}
\end{aligned}
$$

If ec.(5) is substituted in the equation of Poseuille, the relation between the sensing signal of flow will be obtained in the pneumotachometer

$$
\phi=\left(\frac{\pi R^{4}}{8 \mu \Delta x}\right)\left(\frac{V_{\text {amplificado }}}{3.5 m \text { Volts }}\right)-k_{4}
$$

Where: $k_{4}=\left(\frac{\pi R^{4}}{8 \mu \Delta x}\right) k_{3}$
Table 1 Physical parameters in Poseuille equation

\begin{tabular}{|c|c|c|}
\hline $\begin{array}{c}\text { Distance between test } \\
\text { points } \Delta \mathrm{x} \\
(\mathrm{m})\end{array}$ & $\begin{array}{c}\text { Internal of the } \\
\text { nozzle } \mathrm{R} \\
(\mathrm{m})\end{array}$ & $\begin{array}{c}\text { Dynamic viscosity } \mu \text { at } \\
37^{\circ} \mathrm{C} \\
(\mathrm{kg} / \mathrm{m} \cdot \mathrm{s})\end{array}$ \\
\hline 0.025 & Aprox. 0.0107 & $1.90433 \mathrm{E}-5$ \\
\hline
\end{tabular}

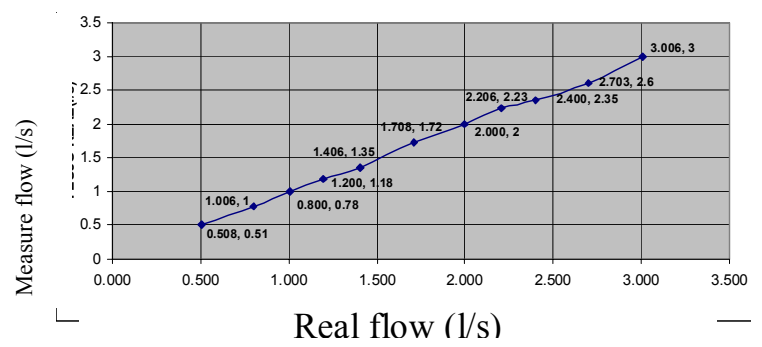

Fig.7 Comparison between designed instrument and a rotameter

Equation (6) implements the operations executed in the signal conditioning system shown in fig 6 , connected to the block labeled like Poseuille. The parameters of the equation (6) correspond to the physical dimensions given in table 1 :

The constant $\mathrm{k}_{4}$ is obtained when reducing the sensed flow before initiating the spirometrics test. Fig 6 shows the diagram of the application for the preparation of signals, whereas figure 7 provides the response obtained from system respect to calibration data.

\section{7, Spirometric results}

As it were mentioned in section 1, the waited for information of a spirometric test are: (1) Graphs of curves volume-time, (2) Graphs of flow-volume, (3) Forced Vital Capacity (FVC), 
(4) Forced Expiratory Volume in the first second (FEV1); and

(5) General information of the patient.

In order to obtain these results, is necessary to have the capacity to store the results of the flow test, and from them, to obtain the corresponding graphs. For space reasons it is not possible to include in this work details about the programming of the interfaces and only the the results obtained will appear. It is possible to consult more details in [21]. In order to evaluate the efficiency of the system as a whole, spirometrics tests to different people were made. The test results as much obey to the efficiency of spirometer, to the physical conditions of the patient and its anthropometric variables. Other factors that can modify the test results are the race, sex, height, weight and age. With the purpose of explaining the operation and evaluating of the instrument designed, one appears the process of a spirometric test and the comparison of data of stored results of a previous measurement. In order to initiate the test the operator will have to ask for the patient who fills his lungs with air. The acquired air of this inspiration will be breathed during the test

In order to begin the examination the button of the left superior part of the screen of the fig. 8 with the legend "Iniciar prueba" must be clicked. Then, the patient who breathes the air must expulse the air with as force as possible and, that he does not let breathe until feeling that all the air inside its lungs has been exhausted. In the right side of the screen the graphs Flow-Time and Volume-Time will be observed, that are the curves obtained of the direct measurement. In the center the spirometrics measurements and the curve of Flow-Volume are showed in real time. To save the information, it is necessary to press the button with the message SAVE that is in the center to the left of the screen.

The stored information of a previous spirometric test will be able to be read. The program will show the same information of the spirometric test, but allowing to compare and to analyze the different tests from a same patient or different patients with similar diagnoses. When working in static way, it is necessary to choose the data files (* LVM), with the information of stored tests. The screen that allows to select the archives (figure 9), will appear 5 times corresponding to the maximum number of tests to show. If a smaller number of archives is desired, then simply need to cancel the election. Once chosen the archives, the read information appears in the main screen, graficada in the curves Flujo-Tiempo and Volumen- Time (figure 9). In these graphs, it is possible to compare the similarities between the tests to evaluate the effort of the patient in each examination and, later, to validate or to reject some sample.

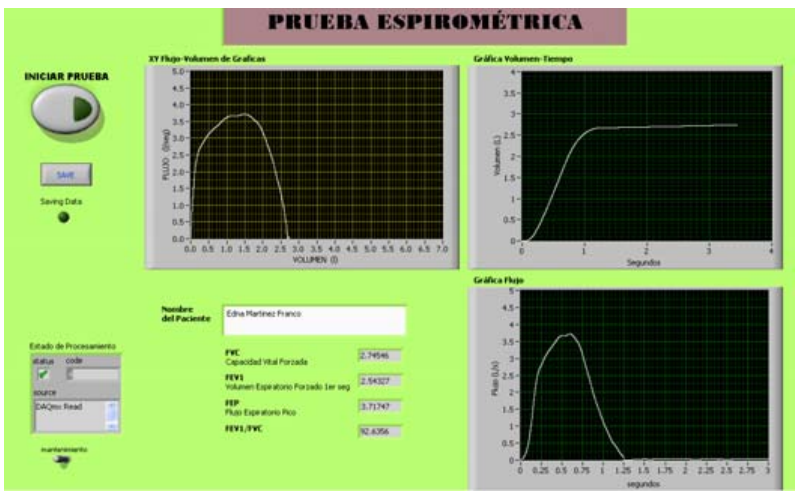

Fig. 8 Main screen of the digital spirometer

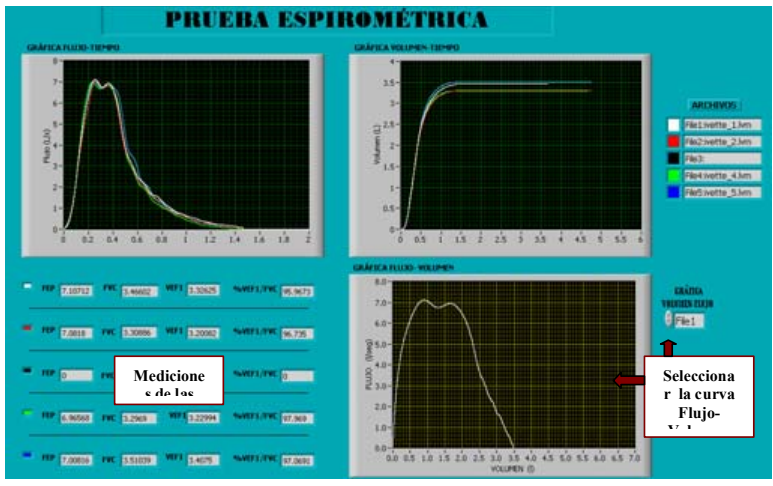

Fig. 9 Comparing different spirometrics test.

According to the norms of the ATS on the visualization of a spirograms, it is required that the graphs keep a minimum relation from $5 \mathrm{~mm}$, 1L for the curve of volume and $2.5 \mathrm{~mm}: 1$ $\mathrm{L} / \mathrm{s}$ for the flow graph, so the clarity in the graphical presentation is guaranteed. By the use ofLabview in the design of the interface, a self-scale can be made that allows fitting the graphs to the values of the measurements, guaranteeing a good visualization.

\section{Conclusions}

The presence of electronics in practically all the aspects of our lives, allows us to appreciate that electronic engineering is applicable in practically any branch of the human knowledge, for the development of a great diversity of tools. The present work shows an electronic application in a very specific branch of the medical area, in the evaluation of the respiratory health by means of the spirometry. Most interesting of a project of 
this type, from the technological point of view, it is the accomplishment of a modern, exact instrument and of low cost that is accessible to all the people and who use the optimal tools for their development. Continuing with the goal to construct economic a medical instrument, a commercial board for data acquisition NI USB-6008 was used. The software made in Labview it consists of two programs: the first one for data acquisition and the second one for data analysis. The programs are friendly and $100 \%$ graphs. It is considered that the obtained results are good and agreed to the propose goals. This work could favor the use of the spirometry in our country when facilitating the acquisition of equipment from low cost to hospitals and clinics in reference to commercial spirometers.

\section{REFERENCES}

[1] Ballesteros M, Rafael (2002). Traumatología y medicina Deportiva. España: Thomson.

[2] Basano L. y Ottonello P(1999). Ventilation Measurement. Measurement, Instrumentation, and Sensors Handbook. EUA:CRC Press.

[3] Bissell,Cynthia.(1996) Aaron's Tracheostomy Page. EUA: http://www.tracheostomy.com/index.html

[4] Ganong, W. (1994). Fisiología Médica. El manual moderno. Ed. 14. México.

[5] Hogg,James, Chu, F. y Utokaparch (2005), S. The Nature of SmallAirway Obstruction in Chronic Obstructive Pulmonary Disease. The New England Journal of Medicine, Vol 350, 2645-2653.
[6] Johnson, Arthur T., et al (2000). The Biomedical Engineering Handbook: 2nd EditionEd. Respiratory System. EUA: CRC Press.

[7] Khazan, Alexander (1994). Transducers and Their Elements. EUA Prentice Hall

[8] Levitzky, Michael G. (1993) Fisiología Pulmonar. México: Noriega Editores

[9] Linares, Marcela, et al (2002). Revista chilena de enfermedades respiratorias, Vol18, No.2. Chile: SCIELO

[10] Medical Electronics(1998). Pulmonary Function Equipment, Spirometers. EUA: Medical Electronics.

[11] Miller M, Hankinson J, et al (2005). Standardisation of Spirometry. En "ATS/ERS Task Force: Standardization of Lung Function Testing". Italia: Eur Respir.

[12] Pérez Padilla, José Rogelio, et al (2001). Reproducibilidad de Espirometrías en Trabajadores Mexicanos y Valores de Referencia Internacional. Salud Pública México. México: Asociación de Investigación Pediátrica.

[13] Pierce R. y Johns D (1995, 2004). The Measurement and Interpretation of Ventilatory Function in Clinical Practice. Australia: National Library of Australia

[14] Prutchi D y Norris M (2005). Design and Development of Medical Electronic Instrumentation. USA: John Wiley \& Sons.

[15] Quanjer H, Tammeling GJ, et al(1993) Lung volumes and forced ventilatory flows. Standadization of lung function tests. European Community for steel and coal.. Official Statement of the European Respiratory Society.

[16] Respirando Vida (Productora).(2005) Espirometría Midiendo La Vida [Video]. México DF: GlaxoSmithKline.

[17] Rodríguez M, Jorge Iván (2002). Manual de Espirometría. México: Manual Pfizer.

[18] Streeter, Victor, et al (1975). Mecánica de los Fluidos. México: Mc Graw Hill

[19] Toledo, Natividad, et al (2001).La espirometría como Herramienta de Diagnóstico. Bioingeniería y Física Médica Cubana. Vol2, No.1. Cuba: Insituto Central de Investigaciones Digitales

[20] Vázquez de la Iglesia,F.(2006) Método para el Estudio de la Función Pulmonar en Los laringectomizados. Acta Otorrinolaringol (pp.275278). España:Universidad de Navarra.

[21] Diseño y construcción de un espirómetro digital con interfaz en Labview. Nydia Ivette Domínguez Martínez. Tesis de licenciatura, UDLA, 2007 